\title{
Components of crowding in a modular seaweed: sorting through the contradictions
}

\author{
M. Laura Lazo, Anthony R. O. Chapman* \\ Department of Biology, Dalhousie University, Halifax, Nova Scotia B3H 4J1, Canada
}

\begin{abstract}
The most common effects of increased density in terrestrial plant populations are reduced rates of growth and reproduction. There are contradictory reports for fucoid seaweeds, whose performance appears to be enhanced by increased density. Density is 1 of 2 components of crowding. The second is plant size. Crowding increases with size for a given density. In modular organisms there are 2 components of crowding, the within-organism component (which increases with ramet density and size) and the extra-organismal component (that is determined by the sizes and densities of whole plants in the stand). Such complexity presents special difficulties in experimental examination of the effects of crowding. Using stands made up of transplants, and by manipulating the length and density of ramets in the plants, we examined the effects of the 2 components of crowding on the performance of the modular seaweed Ascophyllum nodosum. Plant density was not manipulated. We found that low ramet density promoted the formation of new ramets (shoots) and enhanced relative growth rates. As ramet length and biomass are directly correlated, increases in ramet length translated into increased biomass. Conversely, high density promoted reproduction and faster ramet elongation. Plant length had fewer significant effects. Longer individuals depressed the growth of shorter and similarly sized plants. Hence, for $A$. nodosum, ramet density has a wider range of effects than plant length alone. Also, the effect of density differed among response variables. Nevertheless, it is clear, from this and other work, that modular fucoid species respond to crowding in ways that are fundamentally different from terrestrial higher plants.
\end{abstract}

KEY WORDS: Ascophyllum nodosum - Brown seaweed Crowding - Density - Growth - Intraspecific competition - Ramets Reproduction

\section{INTRODUCTION}

Research on seaweed populations has shown unexpected effects of density. A key study of naturally recruited, even-aged stands of Sargassum sinclairii (Schiel \& Choat 1980), later expanded to include Carpophyllum mastocarpum (Schiel 1985), examined stand performance at a variety of densities. The studies found that total yield, plant length, dry weight and reproductive dry weight increased with density. Since growth determines transitions among size classes, and reproductive dry weight determines fertility, it is clear that vitai rates must be affected by density. Percentage of reproductive plants $(94 \%)$ was higher in the low than in the high density $(60 \%)$ stands. However, over

·E-mail: achapman@codium.clara.net an 8 mo period, survivorship was higher for plants at low densities ( $26 \%$ survived) than at high densities (11.9\% survived, Schiel 1985).

The findings led Schiel \& Choat (1980) to propose that seaweed populations are fundamentally different from higher plants. The effects of density on the latter may be summarized in the $-3 / 2$ thinning or power law. Cousens \& Hutchings (1983) showed later that the stands studied by Schiel \& Choat (1980) do not violate this law. The law is expressed in the equation:

$$
w=K d^{-3 / 2}
$$

where $w$ is mean above-ground plant dry weight, $K$ is a constant and $d$ is plant density. In nearly all plant populations, there is a boundary line represented by the following equation:

$$
\log _{10} w=4.3-1.5 \log _{10} d
$$


below which data points fall. The boundary was shown to apply to populations of seaweed (Cousens \& Hutchings 1983). Furthermore, a study of another fucoid, Himanthalia elongata, found that populations conformed with the self-thinning rule (Creed 1995).

Fucus distichus germlings seeded at 3 different densities (over a 400 -fold range) thinned to similar density (about 600 ind $\mathrm{m}^{-2}$ ) over a $2.5 \mathrm{yr}$ period (Ang \& De Wreede 1992). The authors also found that low percentages of variation in measured parameters could be explained by density alone. The finding suggests that there is hardly a simple and explicit density relationship with demographic performance in any real population. The relationships become density vague because of the effects of other, stochastic, processes (Ang \& De Wreede 1992)

Competition effects in stands of marine modular species are largely unexplored. Modular plants are made up by the reiteration of units sometimes called ramets, e.g. shoots or any vegetatively produced unit capable of functional independence (Hutchings 1979). Based on evidence from terrestrial studies, crowding would be expected to shape populations of ramets.

Major discrepancies between terrestrial and marine studies may be summarized as follows:

(1) In terrestrial plant populations, the most common effects of competition are reduced mean plant size (White \& Harper 1970, Harper 1977) and reproductive output (Watkinson 1986, Weiner 1988). In contrast, plant weight and reproductive biomass of 3 Australasian fucoid species increased with density (Schiel 1985). However, high density in Fucus vesiculosus populations resulted in reduced growth and reproductive potential (Creed et al. 1996b).

(2) The growth of a terrestrial plant depends on sizes of neighbours (Westoby 1984), and often decreases with increasing density of larger neighbours (Hutchings 1986). Growth of marine plants may also be dependent on sizes of neighbours (Schiel \& Foster 1986). Canopy thinning enhances recruitment from a 'bank' of pre-existing plants which depresses mean plant length, but may not affect maximum plant length (Creed et al. 1996b). Results from studies in seaweed populations on the effects of distance to nearest neighbour (Chapman \& Goudey 1983) and density (Schiel \& Foster 1986, Dean et al. 1989, Creed 1995) are inconsistent.

(3) Smaller terrestrial plants have higher relative growth rates than larger individuals, but, in competing populations, the smallest members have low or negative rates (Hutchings 1986). Comparable studies on seaweed populations are lacking.

(4) Intraspecific competition in terrestrial species does not necessarily cause ramet mortality (Kays \& Harper 1974). Rather, ramet natality may be density- regulated in a way that precludes overpopulation (Thompson et al. 1990) and intraclone competition (Hutchings \& Mogie 1990). In dense stands, ramet numbers may increase up to a stable level (Hutchings 1979, Westoby 1984). Mechanisms of ramet density regulation are unexplored in seaweed populations.

(5) In dense stands of terrestrial plants, only one or a few ramets per plant may reach full size. The remainder are stunted (Westoby 1984). The development and underlying causes of such highly skewed sizefrequency distributions have yet to be examined in modular seaweed.

Discrepancies between findings for terrestrial and marine species likely stem from the fact that the experimental manipulations and conceptual frameworks used were not similar. The importance of modular structure in studies of seaweed stands has rarely and only recently been acknowledged (McLachlan et al. 1988, Lazo et al. 1989). Studies of terrestrial modular plants assess growth either as biomass or ramet numbers (e.g. Harper 1977), but not both. A modular plant, however, grows with the number and size of its ramets. Plants may be made up of many small vegetative ramets, or few large reproductive units (or any combination thereof) and yet plant biomass may be the same in both cases. Thus, general conclusions cannot be drawn using just 1 variable. Conclusions apply only to the variables considered.

Because of the existing contradictions and confusion, we undertook a comprehensive study of the effects of crowding on Ascophyllum nodosum, a brown seaweed with a modular construction. The ramets of $A$. nodosum consist of linear branched shoots growing from a common holdfast. Short shoots are vegetative and most long shoots become fertile (Lazo 1992 and below). In established stands, holdfast densities are relatively constant through time ( $\AA$ berg 1990, 1992, Lazo 1992). Crowding and, purportedly, stress increase with the length and density of individual ramets. The present study examines the effects of ramet crowding at a constant holdfast density. The study further attempts to distinguish between the effects of 2 components of crowding, ramet density and ramet length, and between the responses of plants and ramets. Attention was paid to issues in the literature listed above. The response of the overall stand (i.e. ramets and plants combined) and causal links of size were not objectives of this study.

\section{MATERIALS AND METHODS}

The species. An Ascophyllum nodosum plant consists of one to hundreds of ramets arising from a holdfast. Fresh weights of individual plants in the studied 
stand can be as high as $9.8 \mathrm{~kg}$. On average, shoots are about $23 \mathrm{~cm}$ long but they can reach up to $170 \mathrm{~cm}$. There is a direct and significant relationship between ramet weight and length (Lazo 1992). Thus, the longer the ramet, the greater the biomass. Holdfasts split and each fragment, with the ramets arising from it, constitutes another plant which grows and multiplies in the same manner. The clonally produced plants are 'biological individuals' which are structurally coherent, physiologically autonomous organisms (Urbanska 1990).

Study site. The population studied was located in

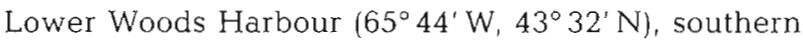
Nova Scotia, Canada. The substratum was composed mainly of large granite boulders fixed in a mixture of sand, mud and cobbles. The stands of Ascophyllum nodosum extended from the intertidal to shallow subtidal and were largely monospecific. Individuals were attached to boulders and thus cover was variable depending on the dispersion of boulders. The stands are harvested commercially.

Experimental design. In naturally occurring stands with relatively constant plant density (Åberg 1990, 1992, Lazo 1992), crowding increases with plant size. Because Ascophyllum nodosum is a modular species, plants grow in size with the number and length of their ramets. Therefore, crowding in the stands increases with the number and length of the ramets within plants. There are thus 2 components of crowding, i.e. ramet density and ramet length within plants. Experiments in this study were designed to discriminate between the effects of variations in the two by manipulating ramet densities and lengths. In the statistical analysis the former factor is simply called 'density'. Because wild $A$. nodosum plants are made up of various combinations of ramet lengths, the variation in ramet length within plants is called 'combination'. Plant numbers (but not ramet numbers) were the same in all experimental stands.

Two levels of ramet density were tested: $300 / 1 / 4 \mathrm{~m}^{2}$ (low) and $900 / 1 / 4 \mathrm{~m}^{2}$ (high, see Fig. 1). The levels are well within the range occurring naturally at our site (maximum 961/1/4 $\mathrm{m}^{2}$ ). There were 5 possible levels of 'combination' which are coded short (S), medium (M), long (L), one-half short/one-half medium (SM), and one-third short/onethird medium/one-third long (SML) (shown in Fig. 1A). The codes are for experimental stands with short, medium and long plants. The 3 plant length classes were made up of combinations of 3 ramet length classes, all common in wild stands.

The effects of 'combination' were tested separately on short, medium and long plants. For example, the performances of short plants in low density S stands were compared with short plants in SM and SML low density stands (Fig. 1B).

All treatment combinations were replicated 6 times at the outset, but losses reduced the level of replication to 4 in most cases. In only 2 treatment combinations was the level of replication retained at 6 (low density, SM; high density, SM). The design was therefore unbalanced, although orthogonal.

Response variables. Effects of crowding components were observed on plants and ramets. Plant growth was assessed as changes in plant biomass and ramet frequencies. Reproduction was measured as frequency of reproductive ramets per plant.

Individual plants were weighed before being placed in the experimental stands, and again upon completion of the study. Absolute growth was the difference in wet biomass between the beginning and end of the study (21 mo period). Relative growth in biomass was the change in $\log _{e}$ mass of the plant during the same period ( $\log _{e}$ final mass $-\log _{e}$ initial mass, Hutchings 1986).

Change in the number of ramets was the difference in the total number of ramets in a plant between the beginning and end of the study. Change as proportions of initial frequencies was also assessed. Only ramets $\geq 4 \mathrm{~cm}$ were considered in the assessment of numbers. The initial number of ramets in a plant was known (see 'Experimental design')

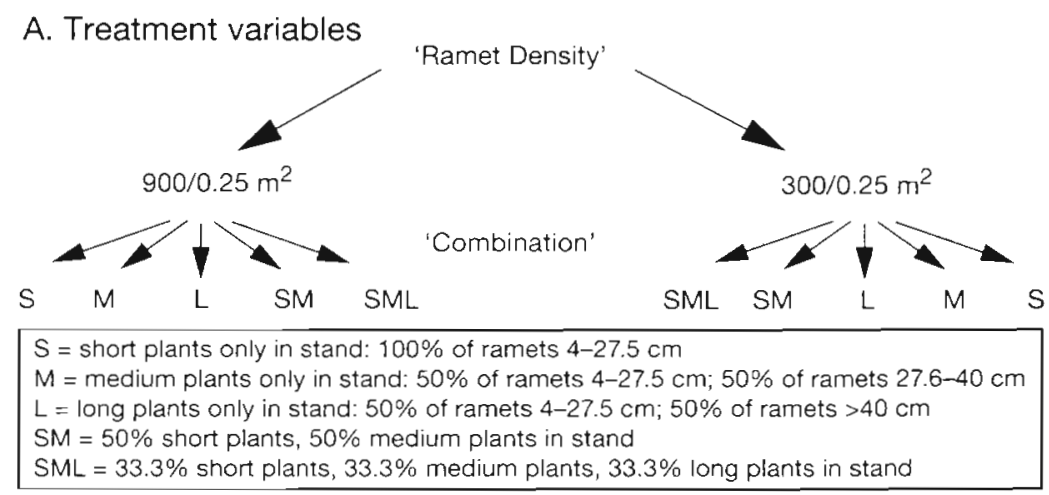

\section{B. Comparisons}

\footnotetext{
1. Performance at 2 densities of short plants in 'combinations' S, SM \& SML

2. Performance at 2 densities of medium plants in 'combinations' $M, S M$ \& SML 3. Performance at 2 densities of long plants in 'combinations' L \& SML
}

Fig. 1. Experimental design. (A) Treatment variables, showing 2 levels of the factor 'density' and 5 levels of the factor 'combination' (B) Comparisons in statistical analyses 
Frequency of reproductive ramets was the difference in the number of reproductive ramets between April 1989 and 1990. On both dates, we counted the number of ramets that attained reproduction in each plant and treatment. When the study began, in July 1988, ramets were in a vegetative state.

Ramet response was assessed as the change in abundance within ramet length classes. Change in abundance was the difference in the number of ramets per length class in a plant between the start and the end of the study (see initial frequencies in 'Experimental design'). The estimate includes ramets that grow into a larger class, that break and move to a smaller one, and that become dislodged, i.e. the net change in number of ramets, not the transition rates. In some cases, plants lost ramets and thus there were fewer in a given class at the end of the study than at the start. Hence, some abundance values were negative.

Statistical analysis. The effects of crowding attributable to ramet densities and combination of ramet lengths within plants on the response variables were analyzed with crossed-factor ANOVAs $(2 \times 2$, or $2 \times 3)$ for each plant length class. There were 5 levels of the factor 'combination', but individual ANOVAs used 2 or 3 levels because each plant length was compared across stands separately (see above and Fig. 1B). Data from each plant length class or ramet length class were averaged for each replicate.

Before running the ANOVAs, tests for normality (Kolmogorov-Smirnov or residual plots) and homoscedasticity (Cochran's) were run. In some cases, log transforms were required. Some values of ramet abundance were negative and thus could not be log transformed. To obtain values greater than zero, the lowest negative value plus 10 was added to each. Data were then transformed. All analyses presented here fit the assumptions.

The power of the performed ANOVAs which yielded non-significant effects was estimated (Zar 1984). If the power was $<80 \%$, and all effects tested in the ANOVA were non-significant, results are not reported. If at least 1 effect in the ANOVA was significant, the table is included in the results.

Implementation. Artificial stands were configured (in the most frequent naturally occurring size/density combinations) from plants collected in the wild. Plants were re-assembled on $1 / 4 \mathrm{~m}^{2}$ segments of metallic mesh. Numbers and lengths of ramets were adjusted to fit the experimental design. Plants which were too long were trimmed down. Plants which were too small were augmented with additional ramets of appropriate lengths. The fragments making up these 'plants' were sewn with fishing line to pieces of polyester fabric which were then attached to the $1 / 4 \mathrm{~m}^{2}$ metallic meshes. Each metallic mesh (i.e. experimental stand) contained
6 'plants' with an appropriate ramet size/density combination. All ramets were in a vegetative state. The artificial stands were interspersed in the mid- to lowintertidal zone in an area without vegetation, immediately adjacent to the original collection site. The experiment was installed in July 1988 and dismantled in April 1990.

Because of routine harvesting, plants with cut ramets were extremely common in our stands. Sometimes, harvesting broke pieces of the holdfast. Also common were plants with holdfasts in close proximity, sometimes physically touching each other, seemingly merging or splitting. During the study, holdfast tissue grew around the fishing line and new ramets were produced. Thus, there was no evidence that the fishing line had a negative effect on the holdfast integrity or growth.

To control for potential artifacts induced by sewing and/or the assembly of plant fragments, we ran a separate experiment simultaneously. Wild plants on small rocks were collected. Each was prepared in the SML array (Fig. 1A) as short, medium and long plants with 50 ramets each. In a few, ramets were cut to fit the 3 length classes. The difference between experimental and control plants was that the latter were naturally attached to the rocks (i.e. not sewn on a mesh) and were not made up of fragments of plants. To maintain the SML configuration, the rocks were cemented in place on a $1 / 4 \mathrm{~m}^{2}$ substratum. The controls for manipulation were made up in triplicate and interspersed with other treatments. The experiment ran between June 1989 and April 1990, when we censused the numbers of ramets in each length class. Comparisons were made within ramet length classes among control and manipulated stands.

\section{RESULTS}

A qualitative summary of treatment effects is presented in Table 1

\section{Formation of new ramets and change in ramet abundance/length class}

Significantly more ramets were produced at low density (300 ramets $\left.\operatorname{stand}^{-1}\right)$ than at high density (900 ramets stand ${ }^{-1}$ ) (ANOVA, $p<0.0001$ ). In the low density stands, a tendency for lower ramet production was noticed when stands contained only plants within single length classes ( $\mathrm{S}, \mathrm{M}$ or $\mathrm{L}, \mathrm{Fig}$. 2a). In high ramet density stands, where all plants were long (L stands), practically no new ramets were produced in 2 yr. However, the factor 'combination' had no significant effect 
Table 1 Ascophyllum nodosum. Qualitative summary of effects of density and 'combination' on selected response variables. + : enhancement; -: negative effect; ns: no significant effect

\begin{tabular}{|c|c|c|}
\hline Response & Treatment & Combination \\
\hline Formation of new ramets & - & ns \\
\hline Ramet abundance in length categories & $\begin{array}{l}\text { Mostly }+ \\
\text { ns in large plants }\end{array}$ & ns \\
\hline Absolute growth rate & + & $\begin{array}{l}\text { ns in whole stands } \\
\text { Long neighbours depress growth in short and long plants }\end{array}$ \\
\hline Relative growth rate & Mostly - & $\begin{array}{l}\text { Mostly ns } \\
\text { Long plants depress growth in short plants }\end{array}$ \\
\hline Frequency of reproductive ramets & + & ns \\
\hline
\end{tabular}

on ramet emergence (ANOVA, $p>0.05$ ). Similar results were obtained when changes in ramet abundance were analyzed as proportions of initial numbers (Fig. 2b). Proportional increases in ramet numbers were 7 times higher at low densities than at high densities.

The responses were broken down by plant length class (short, medium or long). Again, ramet formation was consistently lower in high density stands across all plant length categories (Fig. 3, Table 2). Averaging across the 3 plant length categories, 25 ramets plant ${ }^{-1}$ were formed at high density, and 63 at low density over $21 \mathrm{mo}$. In all categories of plants, the factor 'combination' had no significant effect on ramet formation rates.

At the beginning of the study, ramets in short plants were all $<27.6 \mathrm{~cm}$ long. Two years later, there were ramets in the length categories $27.6-40 \mathrm{~cm}$ and $>40 \mathrm{~cm}$, with fewer in the shortest category than at the beginning (Fig. $4 \mathrm{a}, \mathrm{b}, \mathrm{c}$ ). The number of ramets grow- ing out of the shortest size category was greater at high density than at low density (Table 3 ). High density suppressed the formation of new ramets in the shortest category. The factor 'combination' had no effect on ramet abundance by length category.

The same trends were observed in medium plants (Fig. $4 \mathrm{~d}, \mathrm{e}, \mathrm{f}$ ). At the outset, these had ramets in 2 length categories: $4-27.5$ and $27.6-40 \mathrm{~cm}$. At the end, there were ramets in the longest category $(>40 \mathrm{~cm})$ whose abundance was matched by losses from the next shortest category. The growth of ramets into the longest category from the next shortest occurred more frequently at high than at low ramet density (Table 4). The factor 'combination' again had no significant effect.

At the outset, long plants had ramets in 2 length categories: $<27.6 \mathrm{~cm}$ and $>40 \mathrm{~cm}$. Two years later, there were very few ramets in the intermediate length category $(27.6-40 \mathrm{~cm}$ ) (Fig. $4 \mathrm{~g}, \mathrm{~h}, \mathrm{i})$, indicating limited growth from the shortest length category and limited
Fig. 2. Ascophyllum nodosum Plant responses in low and high density stands with 5 combinations of plant lengths. Data were averaged across short, medium and long plants; see Fig. 1 for explanation of plant length categories. (a) Mean numbers of new ramets formed per plant (b) Data in Fig. 2a expressed as a proportion of pre-existing ramets. (c) Absolute mean increase in mass per plant (d) Mean number of new reproductive ramets per plant. Means + SEs shown

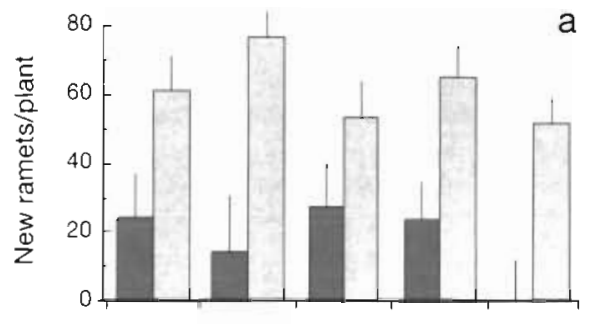

a

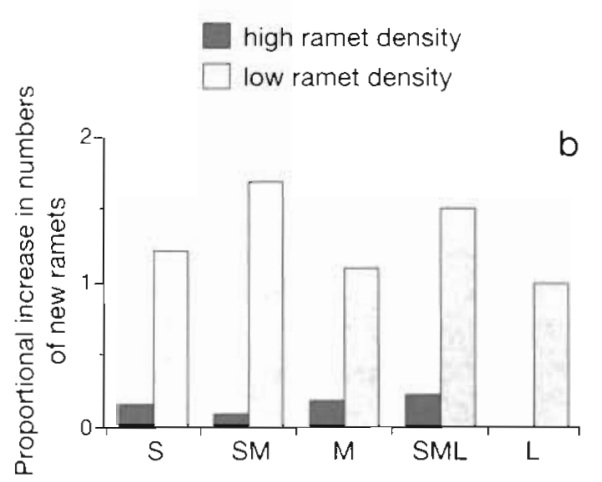

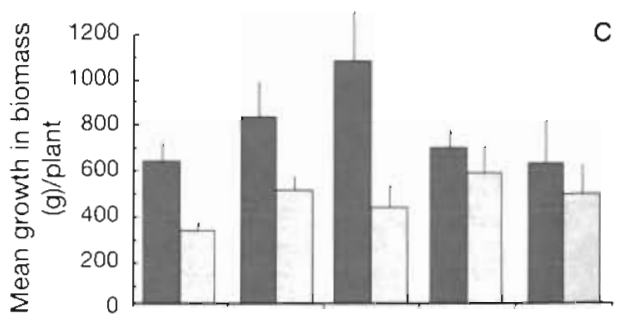

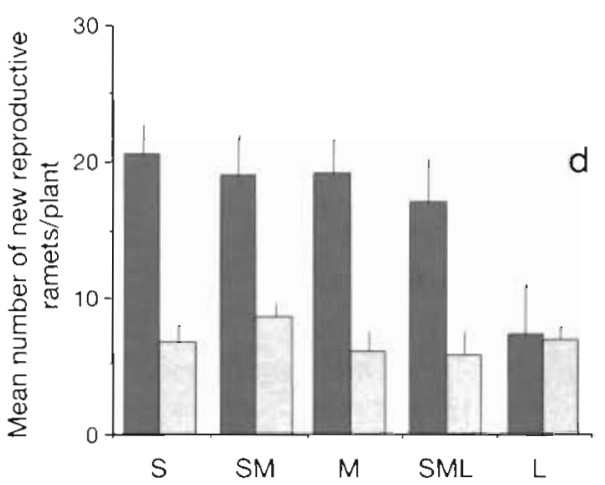




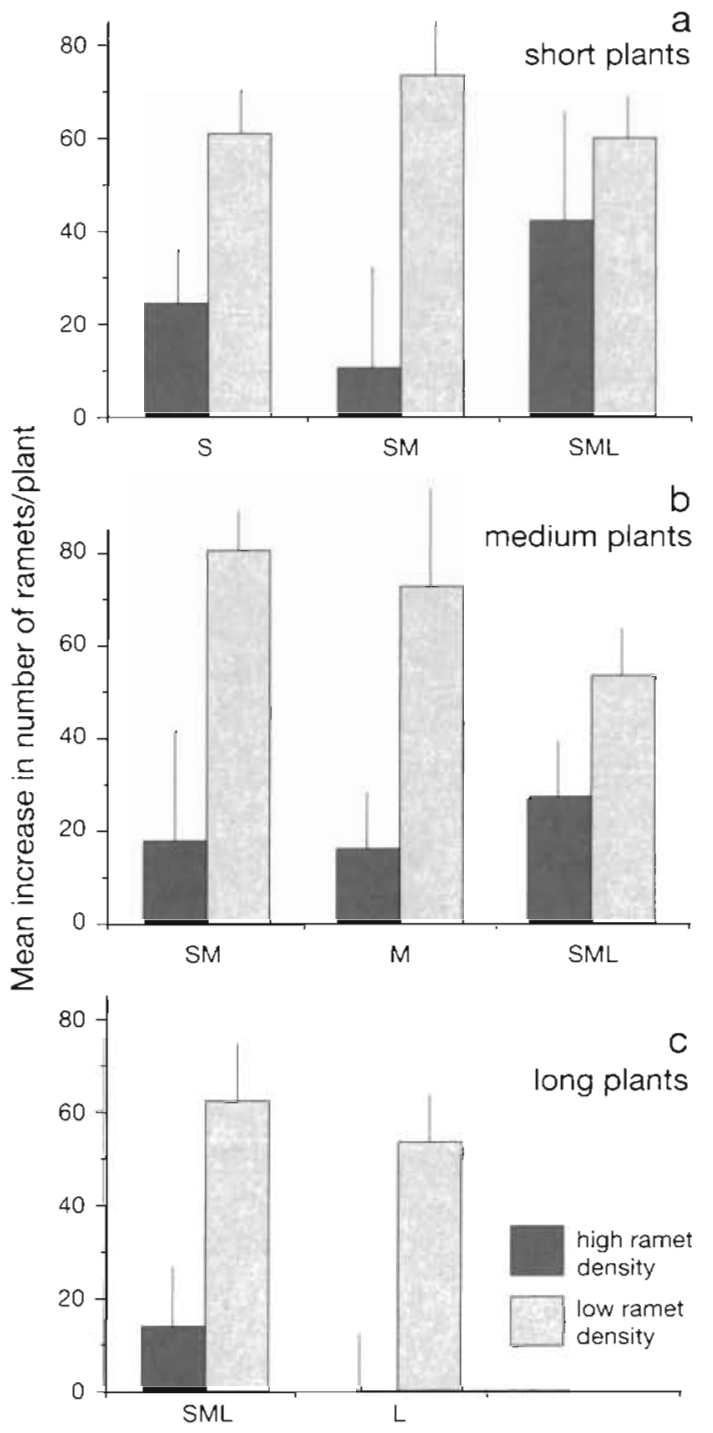

Fig. 3. Ascophyllum nodosum. Mean numbers of ramets formed in (a) short, (b) medium and (c) long plants in low and high density stands with 3 , or 2 for long plants, combinations of plant lengths. See Fig. 1 for an explanation of plant length categories. Means + SEs shown

input from the longest category through breakage. At high ramet densities, the abundance of the longest ramets declined over the experimental period whilst there were minimal losses at low density. No effect of the factor 'combination' was found on ramet abundance within long plants (Table 5).

Changes in ramet abundance were assessed in the experimental test for procedural artifacts. Comparisons were made between plants attached to rocks and 'plants' assembled on 1/4 $\mathrm{m}^{2}$ metallic mesh. No significant differences (pairwise $t$-tests by ramet length category, $p>0.05$ ) were detected. We conclude that artifactual effects of the experimental sewing procedure were not evident
Table 2. Ascophyllum nodosum. Effects of ramet density and combination on the formation of new ramets by plants in each of 3 length classes of plants. Two-way fixed-factor ANOVA

\begin{tabular}{|llrrrc|}
\hline $\begin{array}{l}\text { Plant } \\
\text { length class }\end{array}$ & $\begin{array}{l}\text { Source of } \\
\text { variation }\end{array}$ & df & $\begin{array}{c}\text { Sum of } \\
\text { squares }\end{array}$ & $F$ & $p$ \\
\hline Short & Density & 1 & 8185.73 & 8.46 & $<0.0001$ \\
& Combination & 2 & 386.79 & 0.20 & $>0.05$ \\
& $D \times C$ & 2 & 1757.39 & 0.91 & $>0.05$ \\
& Exror & 18 & 17425.96 & & \\
Medium ${ }^{d}$ & Density & 1 & 0.67 & 15.63 & $<0.0001$ \\
& Combination & 2 & 0.03 & 0.39 & $>0.05$ \\
& $D \times C$ & 2 & 0.09 & 0.01 & $>0.05$ \\
Long & 18 & 0.78 & & \\
& Error & 1 & 7830.24 & 27.37 & 0.003 \\
& Density & 1 & 533.20 & 1.59 & $>0.05$ \\
& Combination & 1 & 2.99 & 0.01 & $>0.05$ \\
& $D \times C$ & 10 & 3350.06 & & \\
Exror & & & & \\
\hline Data $\log _{10}$ transformed & & & & \\
\hline
\end{tabular}

\section{Changes in plant wet mass}

Absolute mean plant weight increased more rapidly in high density stands than in low density stands (ANOVA, p $<0.0001$; Fig. 2c). Hence, density had a positive effect on biomass increases and a negative effect on increases in ramet numbers (Fig. 2a, b vs c). The effects of ramet density were significant in short and medium plants but not in long plants (Fig. 5, Table 6).

The factor 'combination' had no significant effects on absolute mean plant mass when entire stands were taken into consideration (ANOVA, $p>0.05$ ). However, within the plant size categories 'short' and 'long', the factor 'combination' was found to have significant effects (Table 6). In both cases, the presence

Table 3. Ascophyllum nodosum. Effects of ramet density and combination on the abundance of ramets in 3 Jength classes within short plants. Two-way fixed-factor ANOVA

\begin{tabular}{|llrrrr|}
\hline $\begin{array}{l}\text { Ramet } \\
\text { length }(\mathrm{cm})\end{array}$ & $\begin{array}{l}\text { Source of } \\
\text { variation }\end{array}$ & $\mathrm{d}$ f & $\begin{array}{c}\text { Sum of } \\
\text { squares }\end{array}$ & $F$ & $\mathrm{p}$ \\
\hline$<27.6$ & Density & 1 & 28588.59 & 31.50 & $<0.0001$ \\
& Combination & 2 & 174520 & 0.96 & $>0.05$ \\
& $D \times C$ & 2 & 2256.15 & 1.24 & $>0.05$ \\
& Error & 18 & 16334.59 & & \\
$27.6-40$ & Density & 1 & 5172.67 & 48.88 & $<0.0001$ \\
& Combination & 2 & 383.39 & 1.81 & $>0.05$ \\
& D $\times C$ & 2 & 58.50 & 0.28 & $>0.05$ \\
& Error & 18 & 1904.79 & & \\
& Density & 1 & 44.69 & 1.37 & $>0.05$ \\
& Combination & 2 & 11.93 & 0.18 & $>0.05$ \\
& D $\times C$ & 2 & 43.41 & 0.67 & $>0.05$ \\
& Error & 1.8 & 585.39 & & \\
& & & & & \\
\hline
\end{tabular}


Fig. 4. Ascophyllum nodosum. Mean number of new ramets appearing in each of 3 ramet length categories in $(a, b, c)$ short, (d, e, f) medium and (g, $h$, i) long plants. Plants were in low and high density stands with 3 , or 2 for long plants, combinations of plant lengths. See Fig. 1 for explanation of plant length categories. Negative values are losses in a particular ramet length category. Note, losses are matched (approximately) by increases in lower or higher categories. Means + SEs shown
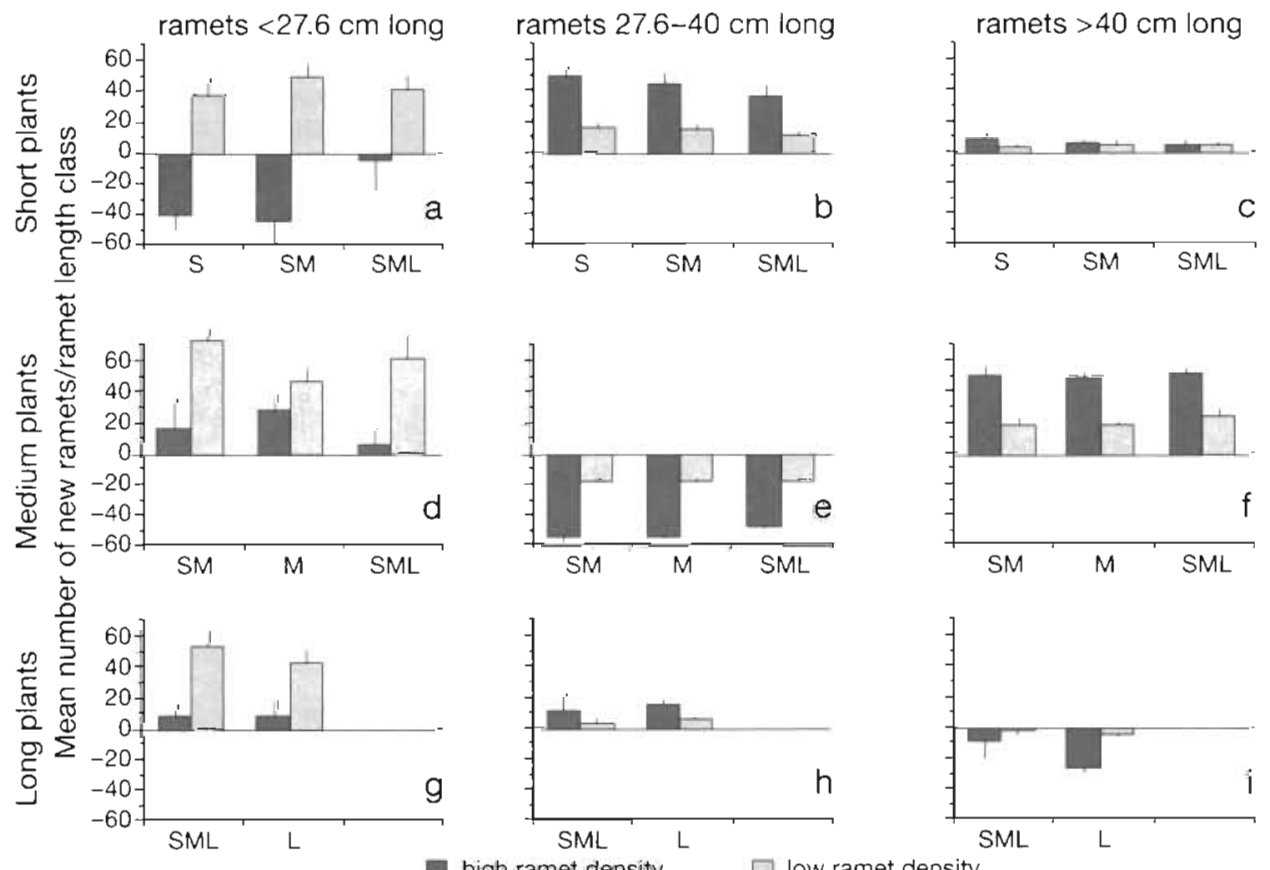

g
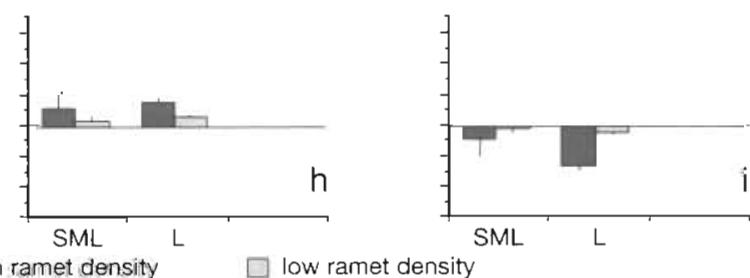

of long neighbours was found to depress growth (Fig. 5)

Relative growth rate in whole stands was higher at low ramet density than at high density, except in $M$ stands where there was no obvious difference. Similar trends were found when responses were broken down by plant length category (Table 7). However, statistically significant effects of density were found only in short plants (ANOVA, $p=0.003$ ). The power of the ANOVAs was very low in tests with non-significant effects. Overall, the direction of effects of ramet density on growth rate (positive or negative) depended on whether absolute or relative rate estimates were used.

The factor 'combination' had statistically significant effects on relative growth rate in short plants only (ANOVA, $p=0.02$ ). Relative growth of short plants decreased with the number of long plants in the stand.

\section{Reproduction}

The abundance of new ramets achieving reproduction increased significantly with density in whole stands and in all plant size categories (Figs. $2 \mathrm{~d} \& 6$, Table 8) with the exception of long plants in L stands (Figs. 2d \& 6), where frequencies were similar among densities. Across all combinations, about 8 and 20 ramets plant ${ }^{-1}$ attained reproductive status at low and high ramet densities, respectively.

The factor 'combination' had no significant effects on reproductive status (Table 8 ).

\section{DISCUSSION}

Because of the indeterminate nature of growth in plants, intraspecific crowding is a function of both density and size. The same is also true of animals, such as mussels, whose growth is indeterminate. In such organisms, it is of little use to consider the effects of density alone. The issue is even more complicated in organisms, such as Ascophyllum nodosum, which have a modular construction. In $A$. nodosum, plant size is a function of the number and length of individual ramets. For these reasons, we examined the effects of

Table 4. Ascophyllum nodosum. Effects of ramet density and combination on the abundance of ramets in 3 length classes within medium plants. Two-way fixed-factor ANOVA

\begin{tabular}{|llrrrc|}
\hline $\begin{array}{l}\text { Ramet } \\
\text { length }(\mathrm{cm})\end{array}$ & $\begin{array}{l}\text { Source of } \\
\text { varnation }\end{array}$ & df & $\begin{array}{c}\text { Sum of } \\
\text { squares }\end{array}$ & $F$ & $\mathrm{p}$ \\
\hline$<27.6$ & Density & 1 & 0.21 & 29.09 & $<0.0001$ \\
& Combination & 2 & 0.01 & 0.76 & $>0.05$ \\
& $D \times C$ & 2 & 0.03 & 2.48 & $>0.05$ \\
& Error & 18 & 0.13 & & \\
$27.6-40$ & Density & 1 & 8114.25 & 646.53 & $<0.0001$ \\
& Combination & 2 & 63.76 & 2.54 & $>0.05$ \\
& D $\times$ C & 2 & 73.85 & 2.94 & $>0.05$ \\
& Error & 18 & 225.91 & & \\
& Density & 1 & 7072.22 & 119.85 & $<0.0001$ \\
& Combination & 2 & 45.24 & 0.38 & $>0.05$ \\
& $D \times C$ & 2 & 43.41 & 0.06 & $>0.05$ \\
& Error & 18 & 1062.22 & & \\
\hline
\end{tabular}


Table 5. Ascophyllum nodosum. Effects of ramet density and combination on the abundance of ramets in 3 length classes within long plants. Two-way fixed-factor ANOVA.

\begin{tabular}{|c|c|c|c|c|c|}
\hline $\begin{array}{l}\text { Ramet } \\
\text { length }(\mathrm{cm})\end{array}$ & $\begin{array}{l}\text { Source of } \\
\text { variation }\end{array}$ & $\mathrm{df}$ & $\begin{array}{l}\text { Sums of } \\
\text { squares }\end{array}$ & $F$ & $p$ \\
\hline$<27.6$ & $\begin{array}{l}\text { Density } \\
\text { 'Combination' } \\
D \times C \\
\text { Error }\end{array}$ & $\begin{array}{r}1 \\
1 \\
1 \\
10\end{array}$ & $\begin{array}{r}120711.2 \\
228846.3 \\
85276.3 \\
259401.7\end{array}$ & $\begin{array}{l}8.38 \\
7.94 \\
2.96\end{array}$ & 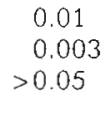 \\
\hline $27.6-40$ & $\begin{array}{l}\text { Density } \\
\text { 'Combination' } \\
D \times C \\
\text { Error }\end{array}$ & $\begin{array}{r}1 \\
1 \\
1 \\
10\end{array}$ & $\begin{array}{r}1431850.7 \\
320818.2 \\
61992.5 \\
1648343\end{array}$ & $\begin{array}{r}15.64 \\
1.75 \\
0.34\end{array}$ & $\begin{aligned} & 0.001 \\
> & 0.05 \\
> & 0.05\end{aligned}$ \\
\hline$>40$ & $\begin{array}{l}\text { Density } \\
\text { 'Combination' } \\
D \times C \\
\text { Error }\end{array}$ & $\begin{array}{r}1 \\
1 \\
1 \\
10\end{array}$ & $\begin{array}{r}1569.8 \\
639089.6 \\
41918.9 \\
1113968\end{array}$ & $\begin{array}{l}0.01 \\
5.74 \\
0.38\end{array}$ & $\begin{array}{r}>0.05 \\
0.04 \\
>0.05\end{array}$ \\
\hline
\end{tabular}
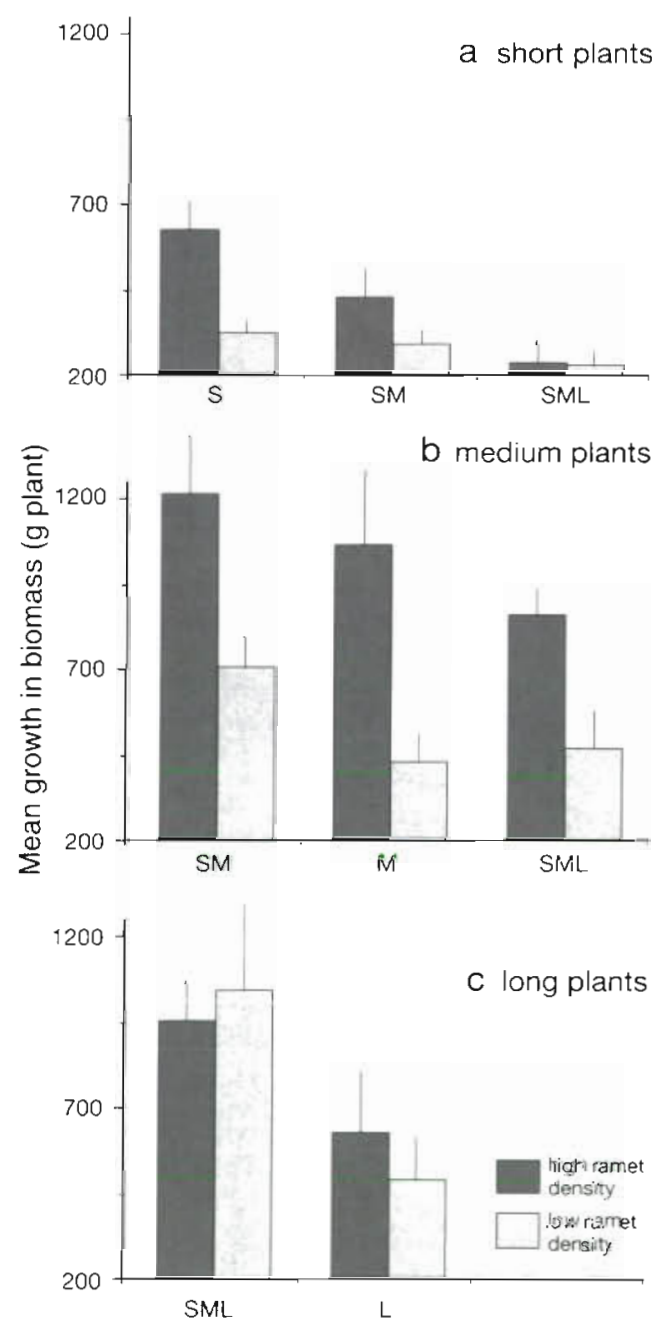

Fig. 5. Ascophyllum nodosum. Absolute mean increase in mass of (a) short, (b) medium and (c) long plants in low and high stands with 3, or 2 in long plants, combinations of plant lengths. See Fig. 1 for explanation of plant length categories. Means + SEs shown
Table 6. Ascophyllum nodosum. Effects of ramet density and combination on absolute changes in weight by plants in each of 3 length classes. Two-way fixed-factor ANOVA

\begin{tabular}{|llrccc|}
\hline $\begin{array}{l}\text { Plant } \\
\text { length class }\end{array}$ & $\begin{array}{l}\text { Source of } \\
\text { variation }\end{array}$ & df & $\begin{array}{c}\text { Sums of } \\
\text { squares }\end{array}$ & $F$ & $\mathrm{p}$ \\
\hline Short & Density & 1 & 120711.2 & 8.38 & $<0.01$ \\
& 'Combination' & 2 & 228846.3 & 7.94 & 0.003 \\
& $D \times C$ & 2 & 85276.3 & 2.96 & $>0.05$ \\
& Error & 18 & 259401.7 & & \\
Medium & Density & 1 & 1431851 & 15.64 & $<0.001$ \\
& 'Combination' & 2 & 320818.2 & 1.75 & $>0.05$ \\
& $D \times C$ & 2 & 61992.5 & 0.34 & $>0.05$ \\
& Error & 18 & 1648343 & & \\
& Density & 1 & 1569.8 & 0.01 & $>0.05$ \\
& 'Combination' & 1 & 639089.6 & 5.74 & 0.04 \\
& $D \times C$ & 1 & 41918.9 & 0.38 & $>0.05$ \\
& Error & 10 & 1113968 & & \\
& & & & & \\
& & & & & \\
& & & & &
\end{tabular}

crowding through manipulation of density and plant length (factors: 'density' $x$ 'combination' of ramet lengths). Density depends on the numbers of ramets per plant and the number of plants per unit area. Plant densities are relatively constant through time ( $\AA$ berg 1990, 1992, Lazo 1992), and so we chose a fixed number of plants per unit area and varied the component ramet densities. Plant sizes were adjusted by manipulating the combinations of long and short ramets for each level of density.

The complexity of modular constructions also presented us with a wide array of potential response variables. We selected variables that would help resolve the contradictions outlined in the 'Introduction'.

The absolute rate of biomass increase was enhanced by increasing ramet density. The finding is consistent with those of Schiel \& Choat (1980) and Schiel (1985), who showed that, in 3 species of New Zealand seaweeds, biomass increased with density. Conversely, density reduces growth rate in land plants (White \& Harper 1970, Harper 1977). Pterygophora californica plants in low density stands also gained in volume significantly more than in high density stands during periods of high growth (Reed 1990). The mechanism by which increasing density enhances absolute growth rates is not immediately apparent. Growth in Ascophyllum nodosum may occur during periods of emergence at low tide (Strömgren 1981, 1983). Metabolic activity in fucoids starts shutting down as dehydration of tissues increases. Crowding of shoots slows down desiccation in clumps of seaweeds (Hay 1981), and this could be the mechanism whereby growth is enhanced in A. nodosum. Bertness \& Leonard (1997) also found that increased density enhanced the growth of $A$. nodosum. In their experimental study, density was varied in combination with shading and shore height. The 
Table 7. Ascophyllum nodosum. Relative growth rates (lnWeight end $_{-}-\ln$ Weight begrnung $_{\text {) }}$ ) of short (S), medium (M) and long (L) plants by density and combination

\begin{tabular}{|c|c|c|c|c|c|c|c|}
\hline \multicolumn{2}{|c|}{ Treatment } & \multicolumn{2}{|c|}{ Short plants } & \multicolumn{2}{|c|}{ Medium plants } & \multicolumn{2}{|c|}{ Long plants } \\
\hline Density & Combination & Mean & $\mathrm{SD}$ & Mean & $\mathrm{SD}$ & Mean & $\mathrm{SD}$ \\
\hline Low & S & 1.80 & 0.18 & & & & \\
\hline Low & SM & 1.50 & 0.36 & 1.42 & 0.44 & & \\
\hline Low & M & & & 1.17 & 0.54 & & \\
\hline Low & SML & 1.54 & 0.26 & 1.17 & 0.15 & 1.20 & 0.49 \\
\hline Low & L & & & & & 0.45 & 0.46 \\
\hline High & $\mathrm{S}$ & 1.50 & 0.50 & & & & \\
\hline High & SM & 1.11 & 0.21 & 1.25 & 0.16 & & \\
\hline High & M & & & 1.12 & 0.40 & & \\
\hline High & SML & 0.67 & 0.36 & 0.84 & 0.13 & 0.51 & 0.15 \\
\hline High & $\mathrm{L}$ & & & & & 0.51 & 0.08 \\
\hline
\end{tabular}

density effect interacted with the other factors. There was no effect of density low on the shore or when shading was applied. The result strongly suggests that increasing density reduces dehydration, which, in turn, promotes growth.

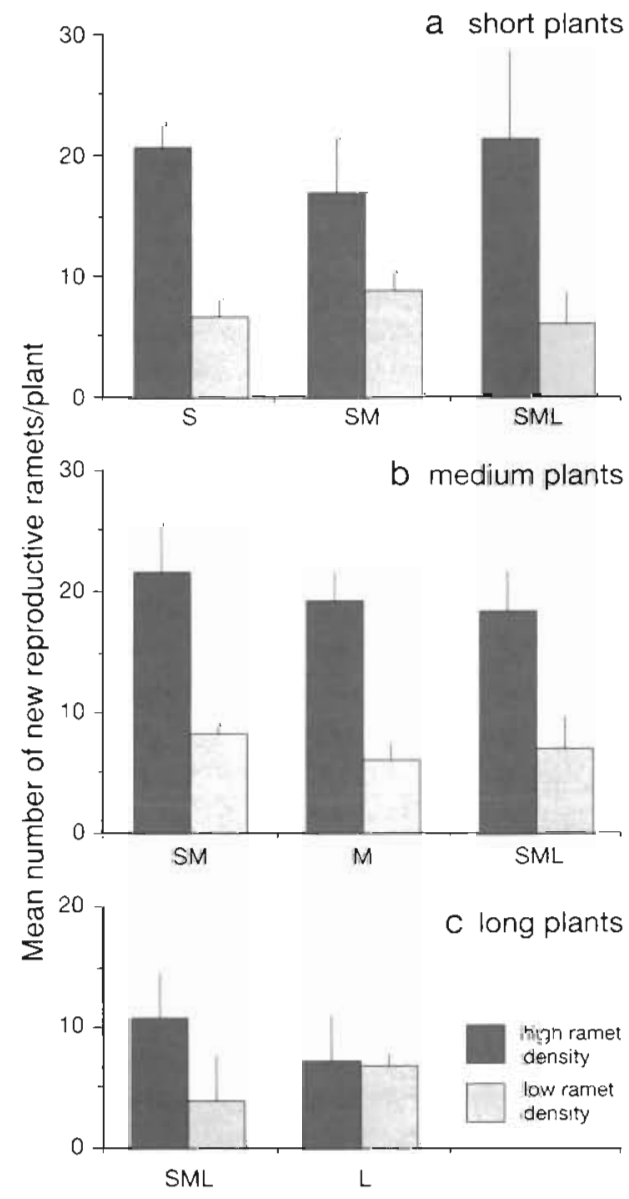

Fig. 6. Ascophyllum nodosum. Mean numbers of new reproductive ramets formed in (a) short, (b) medium and (c) long plants in low and high density stands with 3 , or 2 in long plants, combinations of plant length classes. See Fig. 1 for explanation of plant length categories. Means + SEs shown
The ramets that were present at the beginning of the study grew faster into the longer categories at high density than at low density. The growth to longer classes is the reason for the faster increase in absolute plant mass at higher density. Ramet length structure ('combination') had no significant effect on the growth from one ramet length class to another.

Increasing length of neighbours (factor 'combination') depressed the absolute biomass growth of short plants and of long plants also. This occurred in low and high density stands. The finding is consistent with those for terrestrial plants (Westoby 1984, Hutchings 1986). The effect of 'combination' was more severe in long than in short plants. In the presence of long neighbours when ramet density was low, the absolute weight increase of long plants was depressed by a factor of 8 (comparison between long plants in SML and L stands). In short plants, the presence of longer neighbours (SML vs S stands) depressed growth by a factor of 1.2 . Hence, crowding is even more important for individuals in the canopy than for those underneath. This finding is not consistent with those for land plants.

At low densities, the shortest plants generally had the highest relative growth rates (as biomass increase), as expected. At increased density, the relative growth rate of short plants was higher than the rates of medium and long plants only in the combination $\mathrm{S}$ (short plants only present). In the presence of long plants (combinations SM and SML), the growth of

Table 8. Ascophyllum nodosum. Effects of ramet density and combination on the formation of reproductive ramets by plants in each of 3 length classes. Two-way fixed-factor ANOVA

\begin{tabular}{|llrrrr}
\hline $\begin{array}{l}\text { Plant } \\
\text { length class }\end{array}$ & $\begin{array}{l}\text { Source of } \\
\text { variation }\end{array}$ & df & $\begin{array}{c}\text { Sum of } \\
\text { squares }\end{array}$ & $F$ & $\mathrm{p}$ \\
\hline Short & Density & 1 & 1759.88 & 48.69 & $<0.0001$ \\
& Combination & 2 & 4.46 & 0.06 & $>0.05$ \\
& $D \times C$ & 2 & 43.36 & 0.60 & $>0.05$ \\
& Error & 18 & 650.63 & & \\
Medium & Density & 1 & 2722.51 & 154.98 & $<0.0001$ \\
& Combination & 2 & 26.32 & 0.75 & $>0.05$ \\
& D $\times C$ & 2 & 6.02 & 0.17 & $>0.05$ \\
& Error & 18 & 316.20 & & \\
Long & & & & \\
& Density & 1 & 0.83 & 14.00 & 0.004 \\
& Combination & 1 & 0.00 & 0.00 & $>0.05$ \\
& D $\times C$ & 1 & 0.01 & 0.09 & $>0.05$ \\
& Error & 10 & 0.59 & & \\
& & & &
\end{tabular}

${ }^{\mathrm{a}}$ Data $\log _{10}$ transformed. 
short plants was depressed at high density. All of these findings for relative growth rate are concordant with those for land plants (Hutchings 1986).

In terrestrial plants, increasing density results in reduced ramet natality, and overpopulation is, in this way, avoided (Hutchings \& Moogie 1990, Thompson et al. 1990, De Kroon \& Kwant 1991). Ascophyllum nodosum behaved similarly. It is possible that low levels of illumination at the holdfast (caused by canopy shading) reduce branch inception (Cousens 1982, 1985). However, the length structure of the experimental stands (factor: 'combination') had no significant effect on ramet inception. Since shading must change with plant length, it is perhaps unlikely that variation in light level is the proximate determinant of the density effect.

In addition to enhancing gains in absolute weight. high ramet density increased the abundance of reproductive shoots. The 2 effects are correlated because only the longer shoots achieve reproduction (Lazo 1992), and gains in absolute weight were achieved through length increases in pre-existing shoots and not by the inception of new shoots. Our result is in agreement with the findings of Shiel \& Choat (1980) and Schiel (1985), who demonstrated that fertility and the onset of reproduction in 3 species of New Zealand seaweeds was positively related to density. The positive density-dependence of reproduction in seaweeds contrasts sharply with negatively density-dependent fecundity found in land plants (Watkinson \& Harper 1978). Indeed, the negative form of the relationship is seen as one mechanism by which population density is regulated. If high density depresses fecundity, this has a delayed negative feedback on crowding which is expressed in the next generation. In Ascophyllum nodosum, the issue is complicated because recruitment from zygotes is so rare (Lazo et al. 1994). Nearly all new shoots are added by vegetative regeneration from existing holdfasts. Thus, any influence of density on sexual fecundity will likely have minimal effects in the regulation of population size.

Since most new shoots are added vegetatively to the population, and since ramet natality is negatively density-dependent, it is clear that this is the primary method of population regulation. Of the 2 components of crowding, ramet density and length, only the former has a regulating effect on ramet natality. Indeed, whereas ramet densities had both positive and negative effects on most of the response variables tested, the length structures of the stands had far fewer significant effects. Furthermore, we had expected density effects to operate interactively with stand length structure since crowding should increase with both density and ramet length. In fact, the interaction between density and length was not important. Surprisingly, we found that as in populations of animals with determinate growth, density alone can be considered a regulator of demographic processes. It is not immediately clear why plant length is a relatively unimportant component of crowding in Ascophyllum nodosum. The most likely resource in limiting supply may be light beneath the canopy, as has been found in terrestrial modular species (see Deregibus \& Trlica 1990, De Kroon \& Kwant 1991), although nutrient supply may also be important (Creed et al. 1996b). At both high and low tide, the canopy of longer plants would appear to capture most of the light resource, and on this basis alone, we would have expected an effect of stand length structure. At this point, the issue remains enigmatic. It may well be that our findings apply only to long-lived modular species. Discrepancies with conventional theories, however, will emerge only if experimental design and response variables take into account the modular structure of the species.

Acknowledgements. We sincerely thank Drs R. De Wreede and D. Schiel for their critical review of this paper. The field program was done with great assistance from John Markham. Judith Skeat and Greg Croft also worked in the field. Glyn Sharp acted as our government liaison officer and helped with practical aspects at the beginning of the field work. We are grateful to all of them. Protan Scotia Marine provided supporting funds. Most funding came through a grant from NSERC Canada and from Fisheries and Oceans Canada to A.R.O.C. M.L.L. was supported by Dalhousie graduate scholarships.

\section{LITERATURE CITED}

Aberg P (1990) Size based transition matrix study in two populations of the seaweed Ascophyllum nodosum. $\mathrm{PhD}$ thesis, Göteborg University

Åberg P (1992) Size based demography of the seaweed Ascophyllum nodosum in stochastic environments. Ecology 73 : $1488-1501$

Ang PO, De Wreede RE (1992) Density-dependence in a population of Fucus distichus. Mar Ecol Prog Ser 90:169-181

Bertness MD, Leonard GH (1997) The role of positive interactions in communities: lessons from intertidal habitats. Ecology 78:1976-1989

Chapman ARO, Goudey C (1983) Demographic study of the macrothallus of Leathesia difformis (Phaeophyta) in Nova Scotia. Can J Bot 61:319-323

Cousens $R$ (1982) The effect of exposure to wave action on the morphology and pigmentation of Ascophyllum nodosum (L.) Le Jolis in South-Eastern Canada. Bot Mar 25:191-195

Cousens R (1985) Ramet size distributions and the effects of the algal canopy on the behaviour of Ascophyllum nodosum (L.) Le Jolis. J Exp Mar Biol Ecol 92:231-249

Cousens R, Hutchings $M$ (1983) The relationship between density and mean ramet weight in monospecific seaweed stands. Nature 310:240-241

Creed JC (1995) Spatial dynamics of Hymanthalia elongata (Fucales, Phaephyta) populations. J Phycol 31:851-859

Creed JC, Norton TA, Harding SP (1996a) The development of size structure in a young Fucus serratus population. 
Eur J Phycol 31:203-209

Creed JC, Norton TA, Kain (Jones) JM (1996b) Are neighbours harmful or helpful in Fucus vesiculosus populations? Mar Ecol Prog Ser 133:191-201

Dean T, Thies K, Lagos S (1989) Survival of juvenile giant kelp: the effects of demographic factors, competitors, and grazers. Ecology 70:483-495

De Kroon H, Kwant R (1991) Density-dependent growth responses in two clonal herbs: regulation of shoot density. Oecologia 86:298-304

Deregibus V. Trlica M (1990) Influence of defoliation upon tiller structure and demography in two warm-season grasses. Acta Oecol 11:693-699

Harper J (1977) Population biology of plants. Academic Press, London

Hay ME (1981) The functional morphology of turf-forming seaweeds: persistence in stressful marine habitats. Ecology $62: 739-750$

Hutchings $M$ (1979) Weight-density relationships in ramet populations of clonal perennial herbs, with special reference to the $-3 / 2$ power law. J Ecol 67:21-33

Hutchings $M$ (1986) The structure of plant populations. In: Crawley M (ed) Plant ecology. Blackwell Scientific Publications, Oxford, p 97-136

Hutchings M, Mogie M (1990) The spatial structure of clonal plants: control and consequences. In: van Groenendael J, de Kroon $\mathrm{H}$ (eds) Clonal growth in plants: regeneration and function. SPB Academic Publishing, The Hague, p $57-76$

Kays S, Harper J (1974) The regulation of plant and tiller density in a grass sward. J Ecol 62:97-105

Lazo ML (1992) Demography of harvested populations of Ascophyllum nodosum. PhD thesis, Dalhousie University

Lazo ML, Markham J, Chapman ARO (1994) Herbivory and harvesting: effects on sexual recruitment and vegetative modules of Ascophyllum nodosum. Ophelia 40:95-113

Lazo ML, Greenwell M, McLachlan J (1989) Population structure of Chondrus crispus (Gigartinaceae, Rhodophyta) along the coast of Prince Edward Island, Canada: distribution of gametophytic and sporophytic fronds. J Exp Mar Biol Ecol 126:45-58

McLachlan J, Lewis NI, Lazo ML (1988) Biological considera-

Editorial responsibility: Otto Kinne (Editor),

Oldendort/Luhe, Germany tions of Chrondus crispus Stackhouse (Rhodophyta, Gigartinaceae) in the southern Gulf of St. Lawrence, Canada. Gayana Bot 45:29-54

Reed DC (1990) An experimental evaluation of density dependence in a subtidal algal population. Ecology 71 2286-2296

Schiel DR (1985) Growth, survival and reproduction of two species of marine algae at different densities in natural stands. J Ecol 73:199-217

Schiel DR, Choat JR (1980) Effects of density on monospecific stands of marine algae. Nature 285:324-326

Schiel DR, Foster MS (1986) The structure of subtidal algal stands in temperate waters. Oceanogr Mar Biol Annu Rev 24:265-307

Strömgren $T$ (1981) Individual variation in apical growth rate in Ascophyllum nodosum (L.) Le Jolis. Aquat Bot 10 $377-382$

Strömgren T (1983) Temperature-length growth strategies in the littoral alga Ascophyllum nodosum (L.) Limnol Oceanogr 28:516-521

Thompson J, Gray A, McNeilly T (1990) The effects of density on the population dynamics of Spartina anglica. Acta Oecologica 11:669-682

Urbanska KM (1990) Biology of asexually reproducing plants. In: Kawano S (ed) Biological approaches and evolutionary trends in plants. Academic Press, London, p 273-292

Watkinson AR (1986) Plant population dynamics. In: May M (ed) Plant ecology. Blackwell Scientific Publications, Oxford, $p$ 137-184

Watkinson AR, Harper JL (1978) The demography of a sand dune annual Vulpia fasciculata. I. The natural regulation of populations. J Ecol 66:15-33

Weiner J (1988) The influence of competition on plant reproduction. In: Lovett Doust $J$, Lovett Doust L (eds) Plant reproductive ecology: patterns and strategies. Oxford University Press, New York, p 228-245

Westoby $M$ (1984) The self-thinning rule. Adv Ecol Res 14 $167-225$

White J, Harper JL (1970) Correlated changes in plant size and number in plant populations. J Ecol 58:467-485

Zar J (1984) Biostatistical analysis. Prentice-Hall, Inc, New York

Submitted: April 15, 1997, Accepted: July 3, 1998

Proofs received from author(s): November 13, 1998 